\title{
A RELAÇÃO ENTRE O MERCADO DE DÍVIDA PÚBLICA E A POLÍTICA MONETÁRIA NO BRASIL*
}

\author{
Rafael Quevedo do Amaral ${ }^{*}$
}

José Luis Oreiro ${ }^{* * *}$

\begin{abstract}
RESUMO O objetivo deste artigo é discutir e analisar a relevância da dívida pública, particularmente de sua duração, como um importante canal de transmissão da política monetária. Procura-se argumentar que a característica do mercado de dívida pública no Brasil, fortemente concentrado em títulos pós-fixados, especialmente em Letras Financeiras do Tesouro, retira parte da eficácia da política monetária. Dado que as LFTs são títulos com valor de face imune a variações na taxa de juros e que aproximadamente metade da dívida pública está indexada a tais títulos, um importante canal de transmissão da política monetária, o efeito riqueza, é interrompido.
\end{abstract}

Palavras-chave: política monetária; dívida pública; títulos públicos

Código JEL: E63, E43, E47

\section{THE RELATION BETWEEN THE MARKET OF PUBLIC DEBT AND THE MONETARY POLICY IN BRAZIL}

ABSTRACT The objective of this article is to argue and to analyze the relevance of the public debt, particularly of its duration, as an important monetary policy mechanism transmission. It is looked to argue that the characteristic of the public debt market in Brazil, strong concentrated in post-fixed assets, especially in Treasure's

\footnotetext{
* Artigo recebido em 2 de abril de 2007 e aprovado em 15 de agosto de 2008.

** Economista do Departamento Nacional de Produção Mineral/Ministério de Minas e Energia e mestre em Desenvolvimento Econômico pela Universidade Federal do Paraná (UFPR), e-mail: quevedoam@yahoo.com.br

*** Professor do Departamento de Economia da Universidade Federal de Brasília e pesquisador do CNPq, e-mail: joreiro@ufpr.br
} 
Financial Letters, removes part of the monetary policy effectiveness. Considering that the LFTs are assets with face value immune to variations in the interests rate and that approximately half of public debt is index to such assets, an important mechanism of monetary policy transmission, the wealth effect, is interrupted.

Key words: monetary policy; public debt; public bonds 


\section{INTRODUÇÃO}

O efeito riqueza ${ }^{1}$ pode ser considerado um dos canais de transmissão da política monetária. No Brasil, contudo, tal efeito está comprometido pela excessiva participação na dívida pública de títulos pós-fixados e sem risco de taxa de juros (LFTs). Nesse contexto, as variações necessárias na taxa de juros são maiores do que as que ocorreriam caso o efeito riqueza operasse em maior magnitude. Além disso, como não há risco de taxa de juros, variações desta atuam no sentido de criar um efeito renda positivo, o que diminui ainda mais o poder dos juros como instrumento de política monetária.

Para analisar a relação entre a dívida pública brasileira e a perda de eficácia da política monetária é apresentada inicialmente, na primeira seção, a formação dos preços dos principais títulos da dívida pública. Mostram-se também o histórico das LFTs no Brasil e a evolução da composição da dívida nos últimos anos, dando-se forte ênfase à sua duração e prazo médio. $\mathrm{Na}$ mesma seção procura-se explicar a peculiaridade das Letras Financeiras do Tesouro e por que sua grande participação na dívida retira eficácia da política monetária e dificulta a queda dos juros no país.

Na segunda seção é apresentado um modelo macroeconômico de política monetária com expectativas racionais e Duration, em que o objetivo principal é ilustrar matematicamente a hipótese de que a baixa duração da dívida pública retira eficácia da política monetária e impede uma queda mais acentuada da taxa de juros. O modelo é resolvido para os valores de equilíbrio das variáveis endógenas e simulado no tempo, onde são analisados o comportamento das variáveis sob diferentes condições e a importância da Duration na determinação do produto, inflação e taxa de juros.

\section{O MERCADO DE TÍTULOS PÚBLICOS E A CONDUÇÃO DA POLÍTICA MONETÁRIA}

A estrutura da dívida pública brasileira e, por sua vez, o mercado de títulos públicos explicitam uma possível fonte de perda de eficácia da política monetária. Pode-se constatar que essa não é a única, mas a forma como ocorre a ligação entre o mercado de títulos públicos e a política monetária caracteriza uma fonte peculiar de perda de eficácia da política monetária. O problema não advém da necessidade de a política monetária responder a uma ou 
mais variáveis, mas sim do fato de que tal resposta tem seus efeitos enfraquecidos, ou até mesmo distorcidos, pela característica do mercado de títulos da dívida.

O fator determinante desse problema é a grande participação de títulos pós-fixados, mais especificamente as Letras Financeiras do Tesouro (LFTs), na composição da dívida líquida do setor público, doravante denominada DLSP. A participação desses títulos na DLSP chegou a atingir 54,3\% em outubro de 2005, alcançando, em novembro de 2006, 38,7\% (BCB-DEPEC).

As LFTs surgiram em 1986 sob a forma de Letras do Banco Central (LBCs), objetivando a diminuição do custo de rolagem da dívida pública, que se tornava alto com a evidência de fracasso do Plano Cruzado. Quando o congelamento de preços feito no Plano Cruzado se mostrou insustentável, impôs-se a necessidade de elevar fortemente a taxa de juros como forma de evitar o retorno a um cenário de "inflação galopante". Em um contexto em que os grandes detentores de títulos eram as instituições financeiras e a elevação dos juros provocaria perdas consideráveis para eles, surgiu a necessidade de se criar um título indexado ao overnight e sem risco de taxa. Assim, com a emissão de um título remunerado pela taxa de juros fixada pelo Banco Central e com "recontratação diária", evitou-se o risco de uma crise sistêmica. $^{2}$

A mudança de denominação de LBC para LFT surgiu com a Constituição de 1988, que proibiu o financiamento direto e indireto do Banco Central à União, viabilizado anteriormente pelas contas movimento e suprimentos. Com a nova Constituição Federal criou-se a conta única da União no Banco Central, permitindo que este último utilizasse os títulos do Tesouro como instrumentos de política monetária (Marques, 1997). ${ }^{3}$

Dessa forma, a administração monetária não pode ocorrer de forma totalmente independente da administração da dívida pública (Tesouro e BC). Ao definir metas para a taxa Selic e operar no open market, o Banco Central não pode deixar de levar em consideração o impacto de tais políticas sobre o estoque de títulos públicos. Isso porque os efeitos sobre os processos de alongamento e aumento da duração da dívida serão de extrema importância para a própria condução da política monetária.

A própria introdução das LBCs durante o Plano Cruzado é uma confirmação da necessidade de se conciliarem as ações de política monetária com 
a administração da dívida. Nesse período, não sendo possível elevar a taxa de juros e manter o estoque de títulos prefixados sem o desenrolar de uma crise sistêmica, ficou o Banco Central "forçado" a trocar os títulos com risco de perda de capital por Letras do Banco Central, que têm a característica de não possuírem risco de taxa. Esse fato parece ter se consumado desde então, ressurgindo episódios da mesma natureza, por exemplo, durante a crise asiática em 1997 e as crises de marcação a mercado e pré-eleitoral em 2002.

Ambos os eventos atuaram como fatores limitadores do processo de alongamento do prazo médio da dívida, que vinha ocorrendo com a introdução de títulos prefixados e pós-fixados de maior prazo. Dessa forma, o Banco Central e o Tesouro Nacional freqüentemente acabam se rendendo à necessidade de recomprar títulos do mercado com o objetivo de preservar a liquidez destes e garantir a rolagem da dívida pública (Ferreira, Robotton e Dupita, 2004).

Dessa forma, retira-se parte do efeito riqueza da política monetária. Esse efeito opera da seguinte forma: mudanças na política monetária afetam o valor dos ativos que, por sua vez, afetam os gastos dos consumidores com serviços e bens de consumo (Ludvigson, Steindel e Lettau, 2002). Considerando que o efeito riqueza, ou seja, o impacto que mudanças nos juros exercem sobre a riqueza financeira dos agentes e, portanto, sobre sua possibilidade de consumo e investimento, é um dos canais de transmissão da política monetária, dois problemas tornam-se evidentes.

Primeiro, a venda de títulos com cláusula de recompra elimina ao menos parte do efeito riqueza da política monetária. Segundo, a magnitude da participação das LFTs na dívida mobiliária, dada a característica peculiar de formação do preço desse título, faz, mais uma vez, com que o efeito riqueza da política monetária seja inexpressivo.

Os dois fatores citados no parágrafo anterior atuam como um limitador na capacidade de se conduzir uma política monetária com maior eficácia. Ao se retirar o efeito riqueza como um canal de transmissão da política monetária, mudanças na taxa de juros deixam de ter o efeito contracionista desejado. Ainda, dependendo da participação das LFTs no estoque da dívida e da disponibilidade da autoridade monetária em recomprar títulos prefixados, ou trocá-los por LFTs em momentos de crise, o efeito de mudanças na taxa de juros pode ser o inverso do esperado. Isso pode ocorrer pelo 
simples fato de que, ao se retirar o efeito riqueza, elevações da taxa de juros atuarão somente no sentido de valorização dos ativos, dada a característica de duração zero das LFTs. ${ }^{4}$

Cabe aqui uma distinção importante: a diferença entre os conceitos de maturidade e duração. A duração diferencia-se do prazo do título, sendo a primeira o efeito da taxa de juros sobre o preço do título e o segundo o próprio prazo temporal de emissão do ativo. Há ainda um segundo conceito de duração, que pode ser considerado como o prazo médio do título, levandose em conta o valor do dinheiro no tempo. Neste segundo caso, a duração seria dada pela razão entre o fluxo de cupons (juros), descontados da taxa básica de juros, e o valor presente do título.

A peculiaridade da LFT, no que se refere à formação de seu preço, é um fator determinante da distinção desse título com relação aos demais títulos públicos. A forma como é determinado o preço desse título explica o fato de ele ter uma duração zero e, portanto, a possível ineficácia com que pode operar a política monetária. O processo de formação de preço da LFT ocorre de acordo com a seguinte metodologia: ${ }^{5}$

(a) calcula-se a cotação do título, que é dada de acordo com a taxa de ágio ou deságio exigida pelo mercado; ${ }^{6}$

(b) atualiza-se o valor nominal de acordo com um fator de atualização que é dado pela taxa Selic acumulada entre uma data-base e a data de compra do título;

(c) projeta-se o valor nominal para a data de liquidação, que no caso das LFTs é diária e, portanto, o título será diariamente corrigido pela taxa Selic corrente; e

(d) o preço unitário é dado pelo produto da cotação pelo valor nominal projetado.

(1) Cotação $\%=\frac{100}{(1+i)^{D U / 252}}$

(2) $\mathrm{VNA}=\mathrm{R} \$ 1000^{\star}$ atualização

(3) $\mathrm{VNA} /$ projetado $=$ VNA $[(1+\text { Selic })]^{(1 / 252)}$

(4) $\mathrm{PU}=\mathrm{VNA} /$ projetado $^{\star}$ Cotação $\%$

onde: 
(a) PU é o preço unitário da LFT;

(b) Cotação é o coeficiente de correção do preço em função do ágio ou deságio;

(c) $i$ é taxa anual de ágio ou deságio aplicada para o vencimento do ativo;

(d) VNA é o valor nominal do título atualizado pela Selic média acumulada (atualização);

(e) VNA projetado é o valor nominal, já atualizado, na data de liquidação do título, que no caso das LFTs é diária;

(f) DU são os dias úteis acumulados entre a data atual até o vencimento do ativo; ${ }^{7}$

(g) Atualização é a correção do valor nominal do título entre a data-base e a data de compra.

É importante observar que um aumento da taxa Selic não exerce nenhum impacto negativo sobre o preço do ativo, pelo contrário, como o valor nominal é atualizado pela taxa básica, elevações da Selic impactam positivamente o preço unitário do título. Dessa forma, o efeito de uma elevação da taxa Selic sobre o preço do título, apesar de positivo, será próximo de zero. Essa elasticidade do preço de um bond, dada uma mudança percentual no fator de desconto, é a já definida duração do ativo, mais conhecida como Duration de Macauley. Ela pode ser representada da seguinte forma:

(5) $D=\frac{\Delta P}{\Delta i} * \frac{(1+i)}{P}$

No caso das LFTs, como pode ser visto através do processo de formação de preço do título, elevações dos juros não acarretam perdas para o investidor e, portanto, o tempo necessário para que não haja perdas pelo movimento dos juros (duração) é zero. Como a recontratação é diária, além de não haver perda de capital, o título estará sendo sempre remunerado pela taxa de juros corrente. ${ }^{8}$

A característica aqui denominada "recontratação diária” ocorre devido à peculiaridade existente na determinação do preço unitário das LFTs, que têm seu valor indexado à Selic diária. Esse mecanismo é bem definido por Franco (2006), que afirma serem as LFTs a sistematização de um processo. 
Ou seja, conforme o autor, tudo se passa como se fosse oferecida uma garantia ao aplicador ou investidor junto ao Tesouro Nacional de que ele possui um título exatamente equivalente a uma aplicação de um dia feita repetidamente.

Em títulos prefixados os dois conceitos (duração e prazo) tendem a serem confundidos, pois o prazo médio será muito próximo da duração do título. No caso de títulos prefixados e sem pagamentos de cupom, chamados de Bullets, o prazo médio será exatamente igual à duração do ativo. ${ }^{9}$ A presença de cupom diminui a duração do título, pois possibilita que o investidor reaplique o mesmo ao juro vigente e, portanto, precise de menos tempo para não sofrer perdas com o movimento da taxa de juros.

Portanto, sendo nula a duração das LFTs, não há a ocorrência do chamado efeito riqueza derivado de elevações da taxa de juros. Ao contrário do que ocorre com os títulos prefixados, por exemplo, em que aumentos da taxa Selic diminuem o preço de mercado do título e, portanto, "tornam os detentores de tais ativos mais pobres", no caso das LFTs esse mecanismo inexiste.

Uma exceção ao observado no parágrafo anterior foi a crise verificada em 2002, em que fatores ligados às eleições e a antecipação da regra de marcação a mercado - que passou a exigir o registro diário de provisões e prejuízos decorridos de diferenças entre o preço do título em carteira e sua cotação de mercado - levaram a um considerável deságio na cotação das LFTs longas. ${ }^{10}$ Como os fundos possuem em suas carteiras títulos públicos federais, esse processo passou a evitar que resgates de aplicações, ao levar à venda de títulos no mercado secundário e, portanto, a possíveis diferenças entre o valor de carteira e de mercado, implicassem retornos financeiros não materializáveis. $^{11}$

No caso das LTNs, por exemplo, que são títulos prefixados, a precificação ocorre da seguinte forma:

(6) $\mathrm{PUMTM}={\frac{\mathrm{V} \cdot \mathrm{R}}{(i+1)^{\mathrm{DU} / 252}}}^{12}$

onde V.R é o valor de resgate no vencimento, que é fixado em R\$1.000,00 (mil reais). Como o valor de resgate é fixo, elevações da taxa Selic (i) ocasionam queda no preço unitário da LTN. Nesse caso, o mecanismo de transmissão do efeito riqueza opera plenamente. 
O grande problema é que os títulos prefixados representam uma proporção muito pequena do estoque de títulos da dívida pública. Apesar de o Tesouro Nacional estar atualmente obtendo um aumento da participação de tais títulos, acompanhado de um aumento da colocação de títulos indexados a índices de preços e de uma queda abrupta da participação de títulos cambiais, as LFTs continuam a ser o título de maior expressão na dívida pública.

O gráfico 1 ilustra a participação dos principais indexadores da dívida pública. Da observação do gráfico pode-se constatar que a melhora qualitativa ocorrida na indexação da dívida - queda da participação dos títulos cambiais e maior colocação de prefixados e indexados ao IPCA — não ocorreu com a substituição das Letras Financeiras do Tesouro. ${ }^{13}$ Pelo contrário, pode-se constatar que a queda na participação dos títulos cambiais, que se torna bem definida em setembro de 2002, ocorre mediante um simultâneo aumento da participação de Letras Financeiras do Tesouro.

Uma melhora considerável na qualidade da dívida pública só se tornou evidente no final de 2005, quando se passa a observar uma maior colocação de títulos prefixados e uma queda modesta na participação das LFTs. É importante observar que a maior colocação em mercado de títulos prefixados vem ocorrendo desde janeiro de 2003, com a emissão tanto de LTN como de NTN, que são títulos com prazos mais longos. ${ }^{14}$

Gráfico 1: Principais indexadores da dívida pública interna (jan. 2001/jun. 2006)

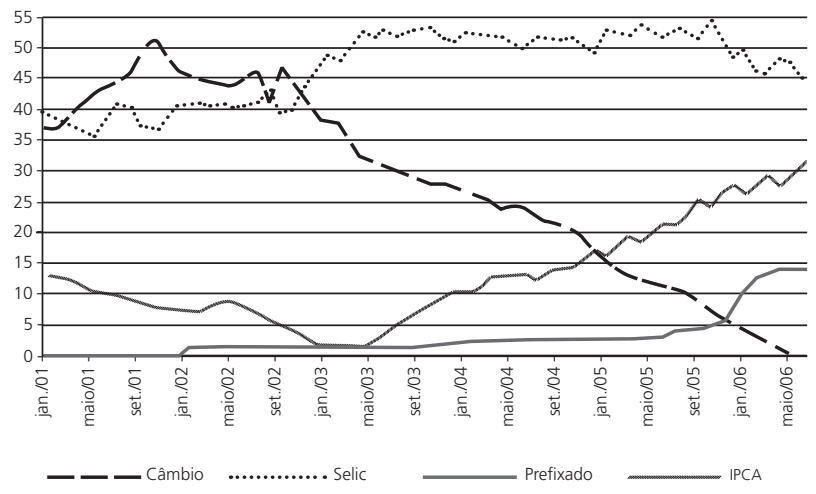


Apesar de as Notas do Tesouro Nacional de série B, C e D sofrerem atualização de acordo, respectivamente, com o IPCA, IGPM e a variação cambial (PTAX), ambas têm a taxa de juros a ser paga definida a priori. Portanto, pode-se considerar que são títulos prefixados em termos de taxa de juros. ${ }^{15}$ O gráfico 2 permite constatar o aumento da colocação em mercado desses dois títulos (NTN e LTN). Apesar disso, a venda de LFT foi, durante todo o período, predominante.

Observando-se o gráfico 3, é possível concluir que há uma queda contínua no prazo médio da dívida mobiliária federal a partir de dezembro de 2002 , fator que só vai ser revertido em dezembro de 2005. Apesar de o prazo médio ter piorado durante todo esse período, a duração da dívida mostrouse ascendente. Esse fator pode ser explicado tanto pela dificuldade de se emitir títulos com prazos mais longos, dado o momento de incerteza que permeava o ano 2002, quanto pela emissão crescente de LTN a partir de março de 2003. Visto que tais títulos são caracteristicamente emitidos com prazos menores do que as LFTs, é possível que a maior colocação deles em mercado explique a queda do prazo médio da dívida.

No mesmo sentido, no final de 2005, com a queda na emissão de LFTs e a maior colocação em mercado de NTN — títulos com prazos maiores —, é possível verificar um processo de melhora no prazo médio da dívida. Outro fator de destaque na explicação desse fenômeno é o aumento do prazo das

\section{Gráfico 2: Saldo da dívida mobiliária em NTN, LTN e LFT, posição em custódia em milhões (jan. 1995/jul. 2006) ${ }^{16}$}

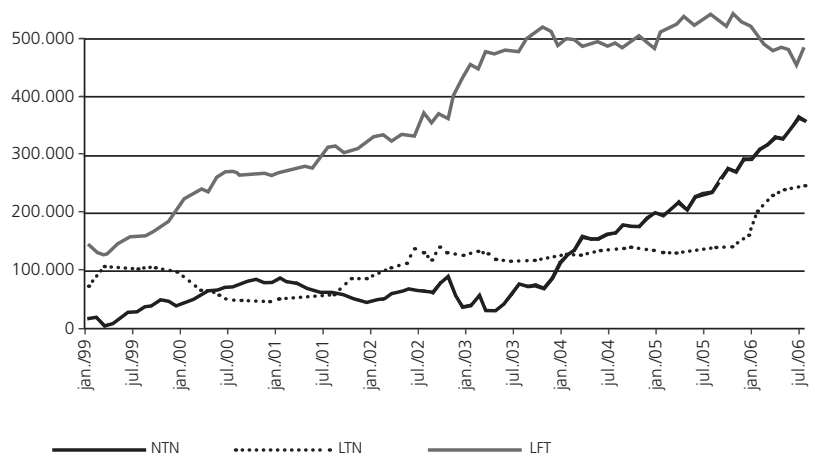


LTNs e NTN-Cs no final do ano. Não se pode deixar de mencionar o momento macroeconômico favorável dos últimos dois anos, fator que explica o alongamento dos prazos dos títulos colocados em mercado.

No que se refere ao comportamento da duração da dívida durante o período analisado (gráfico 3), há uma tendência modesta de aumento da Duration da dívida total. ${ }^{17}$ Tal fator pode ser explicado em parte pelo aumento do prazo/duração das NTNs, ocorrido devido à substituição gradual das NTNs de série D, E, H e S pelas notas de série C e B. ${ }^{18}$ Outro fator a ser considerado é a maior participação desses títulos em mercado, bem como das LTNs.

Não se pode desconsiderar a melhora na duração da dívida, mesmo que tenha sido modesta. Contudo, é significativo o fato de que tanto o prazo médio da dívida mobiliária quanto sua Duration ainda estão aquém do condizente com as conquistas em termos de estabilidade de preços.

Dessa forma, a riqueza financeira tende a se concentrar em aplicações de curto prazo referenciadas na taxa do overnight. Além disso, a grande participação das LFTs na dívida pública dificulta a ampliação do mercado de crédito a taxas mais acessíveis - já que a Selic opera como um custo de oportunidade. Dessa forma, as letras financeiras do tesouro, retiram eficácia da política monetária também sobre esse mecanismo de transmissão, além de poderem estimular um comportamento perverso no mercado de crédito.

Gráfico 3: Prazo médio e duração da dívida mobiliária federal, títulos do Tesouro Nacional (set. 2000/jul. 2006)

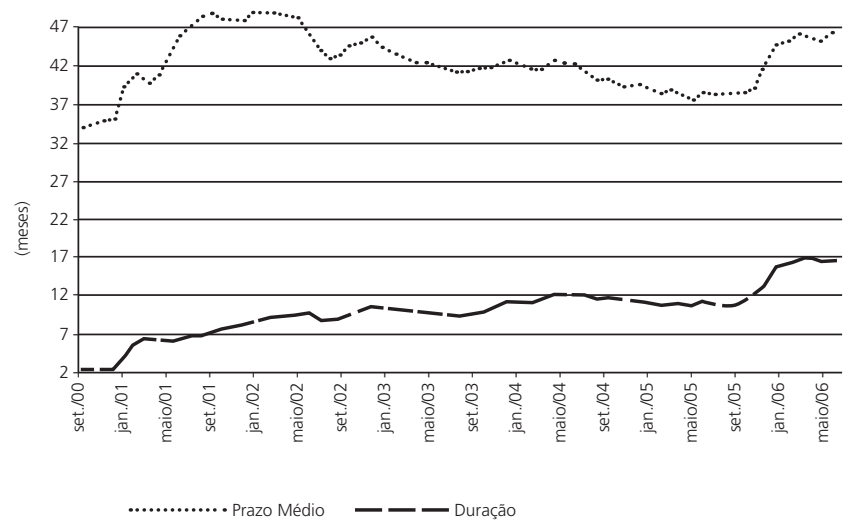


Nesse contexto, a cultura do DI, em que os passivos e ativos de empresas, investidores e bancos são referenciados na taxa do CDI, faz com que a demanda por títulos prefixados seja oriunda majoritariamente de bancos ou fundos de investimento alavancados — fundos multimercados ou hedge funds estrangeiros (Ferreira, Robotton e Dupita, 2004). ${ }^{19}$ Portanto, a demanda pelos títulos prefixados passa a ser uma demanda predominantemente especulativa, em que expectativas de novas elevações da taxa de juros básica restringem a continuidade do processo de elevação da duração da dívida.

Como bem observam Figueiredo e Megale (2006), ao medir o prêmio de risco como a diferença entre o swap pré-DI de 360 dias e a expectativa para a Selic 12 meses à frente, "parece pouco provável que o investidor se arrisque no prefixado para ganhar apenas $2 \%$ a mais, quando ele pode ganhar $19,5 \%$ seguros no pós-fixado”. A possibilidade de fazer uma aplicação equivalente a um dia, com uma taxa de juros próxima à taxa que seria obtida em uma aplicação de longo prazo, faz com que os agentes não financeiros concentrem suas aplicações nos curtíssimo prazo.

Conforme descrevem Ferreira, Robotton e Dupita (2004), o Tesouro Nacional vende os títulos prefixados aos bancos e fundos e estes, por sua vez, vendem aos clientes depósitos e cotas de fundos indexados ao CDI (CDBs e Fundos - DI). Portanto, há um descasamento de prazos, em que os fundos compram títulos prefixados e vendem ativos pós-fixados de um dia. Dessa forma, esses agentes, submetidos a modelos de gestão de risco sofisticados (do tipo Value at Risk - Var), compram papéis sobretudo visando a ganhos de capital. Como demonstram os autores, esse processo acaba tendo um limite, que é ditado pelo próprio modelo de gestão, levando à necessidade de fortes ajustes nas carteiras. Esse ajuste acaba ocorrendo, invariavelmente, com o Banco Central tendo de recomprar os títulos do mercado. ${ }^{20}$

Isso ocorre, predominantemente, pela quase inexistência de agentes não financeiros nas aplicações em títulos prefixados, já que podem obter retornos semelhantes nas aplicações referenciadas no CDI. Nesse contexto, o processo de alongamento da dívida pública e o aumento de sua duração ficam fortemente dependentes de possibilidades de ganhos de capital, abertas em momentos de queda esperada da taxa Selic. Portanto, o mecanismo do efeito riqueza perde força justamente no momento mais necessário, quando a taxa básica tem de ser elevada por qualquer motivo. 


\section{UM MODELO SOBRE A INFLUÊNCIA DA DURATION NA EFICÁCIA DA POLÍTICA MONETÁRIA}

Nesta seção procura-se desenvolver um modelo dinâmico de equações, representativo do contexto de atuação da política monetária em um regime de metas de inflação. Para isso, construiu-se um modelo com seis equações, incluindo uma Curva IS, a Equação de Fisher, uma Regra de Taylor, uma equação de determinação da meta de inflação, uma Curva de Phillips e uma representação da formação de expectativas pelos agentes econômicos. Assume-se que as expectativas são formadas de forma racional e, portanto, que somente um choque exógeno sobre a inflação pode desviar as expectativas da taxa de inflação do período posterior em que são formadas.

Primeiramente, o modelo é descrito e resolvido para os valores de equilíbrio das variáveis, em que são explicados os significados dos coeficientes utilizados e seus valores. Na segunda subseção, procura-se simular o modelo, tanto utilizando os valores iniciais dados aos parâmetros e variáveis quanto fazendo modificações neles com o objetivo de observar o comportamento do sistema ao longo do tempo.

Considerando que o objetivo da simulação feita é de somente observar a trajetória das variáveis, dada alguma mudança nos parâmetros, e que a política monetária, por sua própria natureza, não é administrada de forma estanque, optou-se por limitar a simulação a uma amplitude de 20 períodos. Tal escolha também permitiu que fosse evitada a existência de valores negativos para algumas variáveis, limitando-os a valores condizentes com os observados na economia brasileira. ${ }^{21}$

No mesmo sentido, dado que o objetivo principal é o de modelar a importância do efeito riqueza como mecanismo de transmissão da política monetária, não existindo nenhuma pretensão de construir um modelo de equilíbrio geral para ela, utiliza-se uma equação de demanda agregada em que o impacto da taxa de juros sobre o produto é limitado ao seu efeito riqueza.

Por fim, foram incorporadas à equação de determinação da meta de inflação tanto a meta de curto prazo quanto uma meta de longo prazo. Esta última pode ser entendida como uma taxa de inflação almejada pela autoridade monetária no longo prazo, em que a taxa de inflação estaria em um "ponto ótimo". 22 


\subsection{Modelo de política monetária com a Duration}

\section{da dívida mobiliária}

O modelo de política monetária com Duration proposto contém as equações já mencionadas na introdução desta seção e pode ser descrito da seguinte forma:

(1) $y_{t}=a_{1} y_{t-1}+\left(1-a_{1}\right) \bar{y}-a_{2} D r_{t}+u_{t}$

(2) $r_{t}=i_{t}-E_{t} \partial_{t+1}$

(3) $i_{t}=\tilde{a}_{1} i_{t-1}+\left(1-\gamma_{1}\right)\left(r_{t}+\pi_{t}\right)+\left(1-\gamma_{1}\right) \tilde{a}_{2}\left(\partial_{t}-\partial_{t}^{*}\right)+\left(1-\gamma_{1}\right) \gamma_{3}\left(y_{t}-\bar{y}\right)$

(4) $\pi_{t}^{*}=\pi_{t-1}^{*}+b_{1}\left(\rho_{t}-\pi_{t-1}^{*}\right)+\left(1-b_{1}\right)\left(E_{t} \pi_{t+1}-\pi_{t-1}^{*}\right)$

(5) $\partial_{t}=\ddot{a}_{1} \partial_{t-1}+\left(1-\delta_{1}\right) E_{t} \pi_{t+1}+\delta_{2}\left(y_{t}-\bar{y}\right)+v_{t}$

(6) $E \pi_{t+1}=E\left[\ddot{a}_{1} \partial_{t}+\left(1-\delta_{1}\right) E_{t} \pi_{t+2}+\delta_{2}\left(y_{t+1}-\bar{y}\right)+v_{t}\right]$

As equações apresentadas representam, na mesma ordem em que estão dispostas, as seguintes relações: curva de demanda agregada, ${ }^{23}$ Equação de Fisher, Regra de Taylor, equação de determinação da meta de inflação, Curva de Phillips e equação de formação das expectativas dos agentes para a inflação do próximo período.

onde: $\left(y_{t}, \bar{y}_{t}, D, r_{t}, i_{t}, E_{t} \pi_{t+1}, \pi_{t}, u_{t}, v_{t}\right)$ representam, respectivamente:

- taxa de crescimento do produto $\left(y_{t}\right)$;

- taxa potencial de crescimento do produto $\left(\bar{y}_{t}\right)$;

- Duration da DMFi (D);

- taxa real de juros $\left(r_{t}\right)$;

- taxa nominal de juros $\left(i_{t}\right)$;

- expectativa de inflação para o próximo período $\left(E_{t} \pi_{t+1}\right)$;

- taxa de inflação $\left(\pi_{t}\right)$;

- choque sobre a demanda agregada $\left(u_{t}\right)$;

- choque sobre a taxa de inflação $\left(v_{t}\right)$. 
Podem-se entender as equações apresentadas da seguinte forma: a curva IS representa a taxa de crescimento do produto como uma função da taxa de crescimento no período anterior, do crescimento potencial do produto, do impacto da taxa de juros sobre o produto - que é ponderado pelo tamanho da DMFi e por sua Duration - e de um possível choque exógeno sobre o produto; a Equação de Fisher representa a taxa real de juros como a diferença entre seu valor nominal e as expectativas de inflação; a Regra de Taylor é apresentada como uma função da taxa nominal de juros passada, da soma da taxa real de juros e da taxa de inflação, da diferença entre a inflação efetiva e a meta e do gap do produto; a meta de inflação é função de seu valor no período anterior, da diferença entre a meta de longo prazo e de curto prazo - ponderadas pelo coeficiente de convergência da última para a primeira - e da diferença entre as expectativas para a inflação e a meta fixada no período anterior; por fim, a Curva de Phillips é uma função da inércia inflacionária, das expectativas de inflação, do gap do produto e de um possível choque inflacionário exógeno.

A equação 6 representa somente a maneira como os agentes formam suas expectativas. Como se pode observar, incorporam-se no modelo expectativas racionais, já que são dadas pela própria esperança da Curva de Phillips. A introdução de expectativas no modelo permite representar um ponto central do regime de metas de inflação, ou seja, a possibilidade de mediante a obtenção de credibilidade — reduzir a inflação com um menor sacrifício em termos de produto e emprego.

Por englobar expectativas, necessita-se adotar o método dos coeficientes indeterminados para a resolução do modelo, o que permite eliminar a dependência contínua que as variáveis apresentariam em relação às expectativas de inflação do período subseqüente. ${ }^{24}$ Tal método permite resolver o modelo eliminando o problema da indeterminação.

Para obter as variáveis de equilíbrio, substituem-se, inicialmente, a equação da meta de inflação e a Curva de Phillips na equação da Regra de Taylor, chegando-se a:

(A) $i_{t}=i_{t-1}+\frac{1}{\gamma_{1}}\left\{\begin{array}{l}\left(1-\gamma_{1}\right) \gamma_{3}\left(y_{t}-\bar{y}\right)+\left(1-\gamma_{1}\right)\left(-E_{t} \pi_{t+1}\right)+\left[\left(1-\gamma_{1}\right)+\left(1-\gamma_{1}\right) \gamma_{2}\right] \\ {\left[\delta_{1} \pi_{t-1}+\left(1-\delta_{1}\right) E_{t} \pi_{t+1}+\delta_{2}\left(y_{t}-\bar{y}\right)+v_{t}\right]+\left[\left(-1+\gamma_{1}\right) \gamma_{2}\right]\left[\begin{array}{c}b_{1} \rho_{t}+E_{t} \pi_{t+1} \\ -b_{1} E_{t} \pi_{t+1}\end{array}\right]}\end{array}\right\}$ 
Após substituir a Equação de Fisher na curva IS e a equação (A) na resultante, chega-se a:

(B) $y_{t}=z_{1}+z_{2} E_{t} \pi_{t+1}+z_{3} \pi_{t-1}$

onde:

$z_{1}=\frac{1}{\psi_{1}}\left\{a_{1} y_{t-1}+\left(1-a_{1}\right) \bar{y}+u_{t}\right\}-\frac{a_{2} D}{\gamma_{1} \psi_{1}}\left\{\begin{array}{l}\gamma_{1} i_{t-1}+\left(1-\gamma_{1}\right) \gamma_{3}(-\bar{\gamma})+\left[\left(1-\gamma_{1}\right)+\left(1-\gamma_{1}\right) \gamma_{2}\right] \\ {\left[-\delta_{2} \bar{y}+v_{t}\right]-\left[\left(1-\gamma_{1}\right) \gamma_{2} I b_{1} \rho_{t}\right]}\end{array}\right\}$

$z_{2}=\frac{a_{2} D}{\psi_{1}}+\frac{a_{2} D}{\gamma_{1} \psi_{1}}\left(1-\gamma_{1}\right)-\frac{a_{2} D}{\gamma_{1} \psi_{1}}\left[\left(1-\gamma_{1}\right)+\left(1-\gamma_{1}\right) \gamma_{2}\right]\left(1-\delta_{1}\right)+\frac{a_{2} D}{\gamma_{1} \psi_{1}}\left[\left(-1+\gamma_{1}\right) \gamma_{2}\right]\left(1-b_{1}\right)$

$z_{3}=\left\{\frac{-a_{2} D}{\gamma_{1} \psi_{1}}\left[\left(1-\gamma_{1}\right)+\left(1-\gamma_{1}\right) \gamma_{2}\right] \delta_{1}\right\}$

e

$\psi_{1}=\left\{1+\frac{a D}{\gamma_{1}}\left(1-\gamma_{1}\right) \gamma_{3}+\frac{a_{2} D}{\gamma_{1}}\left[\left(1-\gamma_{1}\right)+\left(1-\gamma_{1}\right) \gamma_{2}\right] \delta_{2}\right\}$

Substituindo a equação B na equação da Curva de Phillips, obtém-se:

(C) $\pi_{t}=-\delta_{2} \bar{y}+\delta_{2} z_{1}+E_{t} \pi_{t+1}\left[\left(1-\delta_{1}\right)+\delta_{2} z_{2}\right]+\pi_{t-1}\left[\delta_{1}+z_{3} \delta_{2}\right]+v_{\mathrm{t}}$

Denominando os termos, respectivamente, $\xi_{0}, \xi_{1}, \xi_{2}, \xi_{3}$ e aplicando o método dos coeficientes indeterminados, encontra-se a seguinte equação de equilíbrio para a taxa de inflação:

(D) $\pi_{t}=\frac{\xi_{0}}{\lambda_{1}}+\phi_{1} \pi_{t-1}+\phi_{2} v_{t}$

onde:

$$
\phi_{0}=\frac{\xi_{0}}{\left[1-\xi_{1}-\xi_{1}\left(1+\frac{\sqrt{1-4 \xi_{1} \xi_{2}}}{2 \xi_{1}}\right)\right]} \quad \phi_{1}=1+\frac{\sqrt{1-4 \xi_{1} \xi_{2}}}{2 \xi_{1}}
$$




$$
\phi_{2}=\frac{\xi_{3}}{\left[1-\xi_{1}\left(1+\frac{\sqrt{1-4 \xi_{1} \xi_{2}}}{2 \xi_{1}}\right)\right]}
$$

e onde $\lambda_{1}$ passa a ser chamado o denominador de $\phi_{0}$.

Por procedimento derivado, $E_{t} \pi_{t+1}=\phi_{0}+\phi_{0} \phi_{1}+\phi_{1}^{2} \pi_{t-1}+\phi_{1} \phi_{2} v_{t}$.

Assim, pode-se chegar à equação da renda de equilíbrio e, por conseguinte, à taxa de juros de equilíbrio:

$$
\begin{aligned}
& y_{t}=z_{1}+z_{2}\left(\phi_{0}+\phi_{0} \phi_{1}+\phi_{1}^{2} \pi_{t-1}+\phi_{1} \phi_{2} v_{t}\right)+z_{3} \pi_{t-1} \\
& (5) i_{t}=\frac{1}{\gamma_{1}}\left\{\gamma_{1} \dot{i}_{t-1}+\left(1-\gamma_{1}\right) \gamma_{3}\left(-\bar{y}_{t}\right)+\left[\left(1-\gamma_{1}\right)+\left(1-\gamma_{1}\right) \gamma_{2}\right]\left(-\delta_{2} \bar{y}_{t}+v_{t}\right)+\right. \\
& \left.\left[-\left(1-\gamma_{1}\right) \gamma_{2}\right]\left(b_{1} \rho_{t}\right)\right\}+\left\{\phi_{0}+\phi_{0} \phi_{1}+\phi_{1}^{2} \pi_{t-1}+\phi_{1} \phi_{2} v\right\}\left\{-\left(1-\gamma_{1}\right)+\left[\left(1-\gamma_{1}\right)+\left(1-\gamma_{1}\right) \gamma_{2}\right]\right. \\
& \left.\left(1-\delta_{1}\right)-\gamma_{2}\left(1-\gamma_{1}\right) .\left(1-b_{1}\right)\right\}+\frac{1}{\gamma_{1}}\left\{\left(1-\gamma_{1}\right) \gamma_{3}+\left[\left(1-\gamma_{1}\right)+\left(1-\gamma_{1}\right) \gamma_{2}\right] \delta_{2}\right\}\left\{z_{1}+z_{2}\right. \\
& \left.\left(\phi_{0}+\phi_{0} \phi_{1}+\phi_{1}^{2} \pi_{t-1}+\phi_{1} \phi_{2} v\right) .+z_{3} \pi_{t-1}\right\}
\end{aligned}
$$

A simulação apresentada na subseção seguinte permite avaliar o comportamento das variáveis ao longo de 20 períodos, bem como as relações entre tal comportamento e mudanças nos valores de alguns dos parâmetros. Tal exercício irá auxiliar a discussão dos resultados apontados pelo modelo.

\subsection{Simulação e resultados do modelo}

Com o objetivo de analisar o comportamento das variáveis no tempo, determinou-se um valor inicial para os coeficientes e variáveis no período $t_{-1}$, conforme expostos nas tabelas 1 e 2 , respectivamente. Os valores estabelecidos para os coeficientes $\gamma_{1}, \gamma_{2}$ e $\delta_{1}$ estão de acordo com os encontrados por Minella et al. (2002). O valor de $a_{2}$, representativo do percentual da DMFi no PIB, foi determinado próximo da média do observado nos últimos anos. Por sua vez, dada a inexistência de estimativas conhecidas para eles, os valores dos parâmetros $\delta_{2}, \gamma_{3}$ e $a_{1}$ foram determinados de forma arbitrária, com exceção de $\delta_{2}$, que foi obtido como o resíduo de $\delta_{1}$. Deve-se salientar que mu- 
danças nos valores destes últimos não alteram os resultados qualitativos encontrados.

Para a conversão da Duration de prazo para variação do preço do título, dada uma mudança na taxa de juros, ou seja, o conceito matemático da duração, procedeu-se da seguinte forma:

$$
\text { Variação do preço }=\frac{- \text { Duração }}{(1+\operatorname{taxa})} \times \text { Variação da taxa }{ }^{25}
$$

Dada uma taxa de juros atual de 13,25\% e considerando uma variação de 1 ponto percentual da taxa de juros, assim como uma duração média de 22 meses, obtém-se uma Duration (variação do preço) de 19,43\%, ou seja, aproximadamente a mesma utilizada no modelo (20\%).

A partir da atribuição de valores para os coeficientes e variáveis (tabelas 1 e 2), foram realizadas diferentes simulações com o modelo. Inicialmente, foram obtidos os resultados para as variáveis no período $t$, conforme dispostos na tabela 3 , e, em seguida, simulado o modelo para 20 períodos (gráfico 4).

Pode-se constatar da tabela 3 que os valores determinados pelo próprio modelo mostram-se coerentes com os encontrados na economia brasileira. Particularmente, os resultados obtidos para o período $t$ estão muito próximos dos valores reais das variáveis observadas no Brasil em 2006 e esperadas para 2007. A meta atual para a inflação no Brasil para 2007 (4,5\%), por exemplo, é praticamente igual à determinada pelo modelo. $\mathrm{O}$ mesmo ocorre com a taxa estimada de crescimento do PIB (3,7\%), para as expectativas quanto ao IPCA anual em 2007, aproximadamente $(3,9 \%),{ }^{26}$ e para a taxa de juros média anual em 2006 (15,47\%).

Analisando a trajetória das variáveis no tempo (gráfico 4), dada a manutenção dos coeficientes com seus valores iniciais, constata-se uma certa estabilidade das variáveis no tempo. O produto, por exemplo, mantém um crescimento médio de 2,8\% (tabela 4). Da mesma forma, tanto a inflação quanto as expectativas para ela - que, por se tratar de um modelo de expectativas racionais, andam sempre próximas ${ }^{27}$ — apresentam-se relativamente estáveis (tabela 4). Essas duas variáveis mostram-se em queda somente a partir do $17^{\circ}$ período, quando a taxa de juros aproxima-se de $20 \%$. 
Tabela 1: Valores dos coeficientes

\begin{tabular}{ccccccccc}
\hline$a_{1}$ & $a_{2}$ & $b_{1}$ & $D$ & $\gamma_{1}$ & $\gamma_{2}$ & $\gamma_{3}$ & $\delta_{1}$ & $\delta_{2}$ \\
0,30 & 0,55 & 0,20 & 0,20 & 0,72 & 1,84 & 0,10 & 0,72 & 0,28 \\
\hline
\end{tabular}

Tabela 2: Valores dados para as variáveis iniciais

\begin{tabular}{ccccc}
\hline$y_{t-1}$ & $\bar{y}$ & $i_{t-1}$ & $\rho$ & $\pi_{t-1}$ \\
0,040 & 0,055 & 0,150 & 0,035 & 0,040 \\
\hline
\end{tabular}

Tabela 3: Valores das variáveis

\begin{tabular}{lcccc}
\hline$y_{t}$ & $i_{t}$ & $\pi_{t}$ & $\pi_{t}^{*}$ & $E_{t} \pi_{t+1}$ \\
0,034 & 0,153 & 0,042 & 0,044 & 0,046 \\
\hline
\end{tabular}

Tabela 4: Resumo comparativo dos resultados (em variação \%)*

\begin{tabular}{lccccc}
\hline Variáveis & Situação inicial & Caso A & Caso B & Caso C & Caso D \\
\hline Inflação & 0,048 & 7,22 & 2,20 & $(2,96)$ & $(4,90)$ \\
\hline Produto & 0,028 & $(0,14)$ & $(0,30)$ & 0,38 & 0,64 \\
\hline Juros & 0,175 & 2,62 & 0,90 & $(1,19)$ & $(1,99)$ \\
\hline Expectativas & 0,047 & 10,92 & 3,48 & $(4,71)$ & $(7,77)$ \\
\hline Meta & 0,044 & 10,15 & 3,00 & $(4,06)$ & $(6,69)$ \\
\hline
\end{tabular}

* A variação é da média dos 20 períodos. Os casos A, B, C e D referem-se, respectivamente, às seguintes situações: Nota:

A. Choque sobre a inflação mantida a Duration constante;

B. Choque sobre a inflação com Duration elevada;

C. Elevação do coeficiente $b_{1}$;

D. Elevação somente da Duration.

Como o objetivo principal do modelo é observar a trajetória das variáveis dado um choque sobre a inflação com diferentes valores para a Duration da DMFi, ou seja, analisar a importância da duração da dívida pública na determinação do efeito riqueza como canal de política monetária, simulou-se também o modelo dando-se um choque sobre a inflação. Para isso, procedeu-se da seguinte forma: primeiramente foi dado um choque sobre a inflação mantido o mesmo valor para a duração da dívida e, em um segundo momento, deu-se o mesmo choque modificando a Duration.

Os gráficos a seguir ilustram as diferentes trajetórias das variáveis para diferentes mudanças nos coeficientes.

Os gráficos 4 e 5 ilustram os resultados dos dois procedimentos. Pode-se constatar dos dois gráficos e da tabela 4 que o choque sobre a inflação tem 
Gráfico 4: Trajetória inicial das variáveis

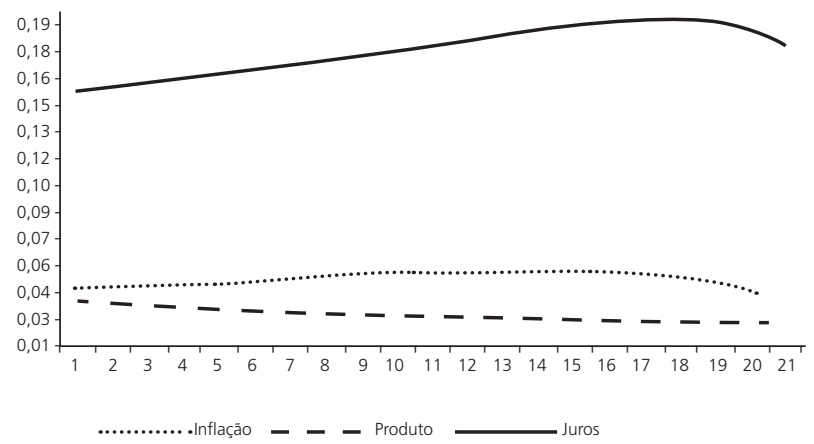

Gráfico 5: Trajetória dado um choque sobre a inflação

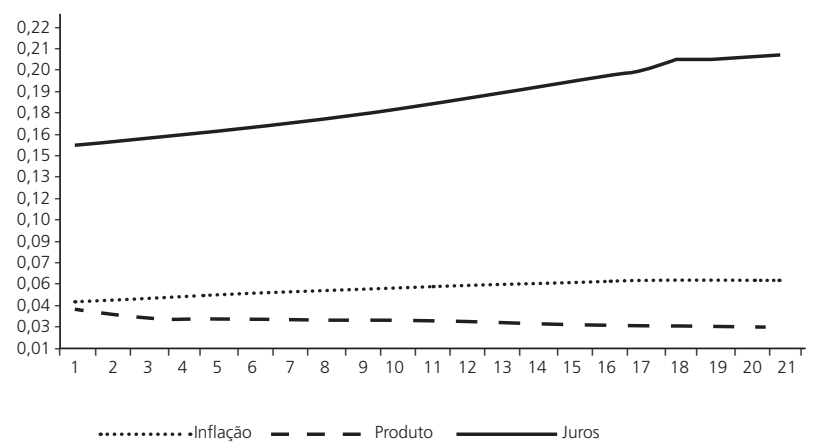

Gráfico 6: Trajetória dado um choque sobre a inflação e elevando-se a Duration

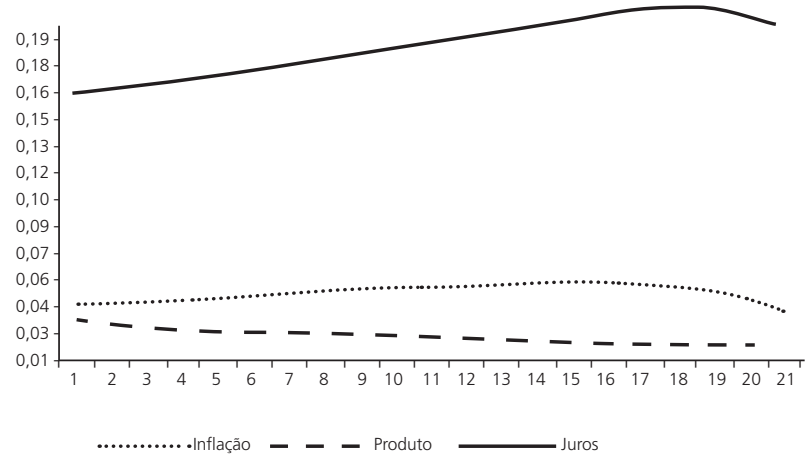


Gráfico 7: Trajetória elevando-se somente a Duration

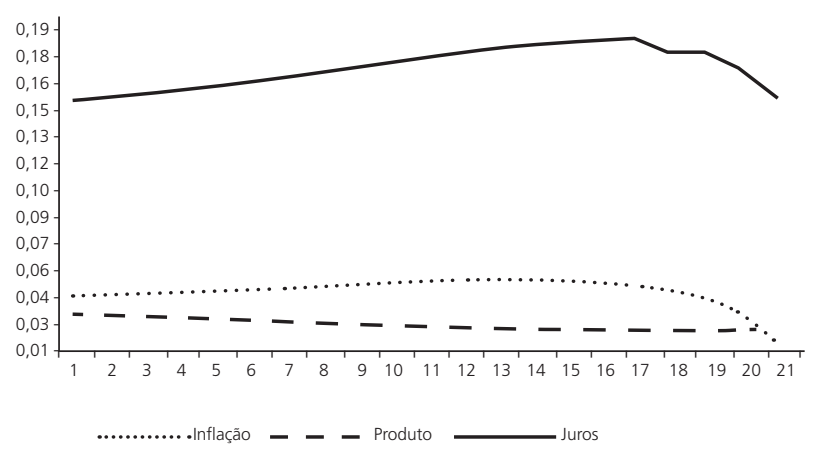

Gráfico 8: Trajetória elevando-se $b_{1}$

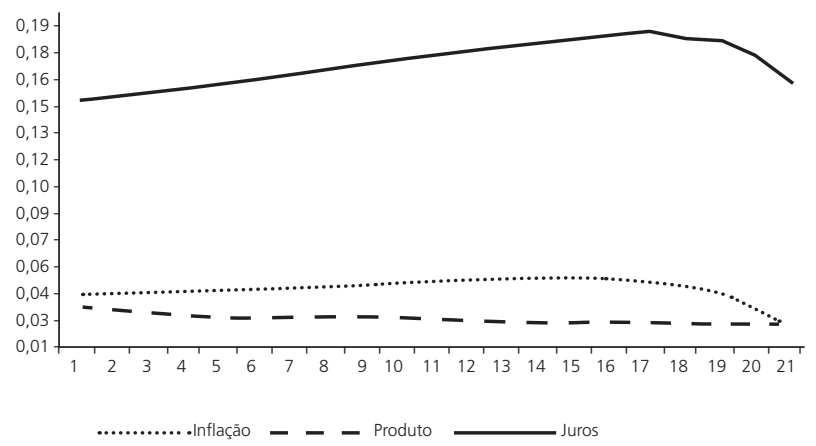

menor influência sobre as variáveis analisadas quanto maior for a duração da dívida e, portanto, o canal de transmissão do efeito riqueza. Apesar de a taxa de crescimento média do produto manter-se a mesma, tanto a taxa de inflação quanto a taxa de juros são menores no caso em que a duração da dívida é elevada, conforme pode ser constatado também do gráfico 7 . De forma análoga à constatada com a elevação da duração da dívida, percebe-se como resultado do modelo que um aumento do coeficiente $b_{1}$ também torna a trajetória das variáveis mais favorável economicamente. A taxa de juros e a inflação tornam-se menores (gráfico 8). Tal resultado parece derivar do fato de considerar-se a existência de expectativas racionais no modelo. Nesse contexto, a elevação do coeficiente sinaliza aos agentes que a autoridade monetária buscará uma convergência rápida para a 
inflação de longo prazo, dando menor importância a desvios das expectativas em relação à meta de curto prazo.

Os resultados encontrados com a simulação do modelo confirmam matematicamente a hipótese de que a elevação da Duration da dívida pública pode ser um fator essencial para uma queda mais acentuada da taxa de juros no Brasil. Além disso, tal fator pode contribuir para que choques sobre a inflação venham a ter impactos de menor magnitude sobre as variáveis. Apesar de o impacto da elevação da Duration sobre o produto ser modesto no modelo, constata-se uma relação positiva, que certamente seria reforçada se fosse considerada a influência da taxa de juros sobre o investimento.

Não se deve perder de vista ainda que taxas de juros menores diminuem o esforço fiscal necessário para cobrir os gastos com juros da dívida, o que possibilita uma realocação de recursos para investimentos essenciais em infra-estrutura, criando as bases para a obtenção de taxas de crescimento sustentáveis.

Nesse contexto, é fundamental que a estabilidade de preços passe a ser conduzida por uma política monetária eficaz e que a própria condução da política monetária não exija uma austeridade fiscal insustentável do ponto de vista tributário e de redução de investimentos públicos essenciais. Não sendo esse o caso, a estabilidade de preços não terá cumprido seu objetivo último: a retomada do crescimento econômico sustentável e da melhoria do bem-estar social.

\section{CONCLUSÃO}

As discussões apresentadas neste artigo corroboram as teorias sobre a existência de uma anomalia na operação da política monetária brasileira. Tal problema não advém somente da grande influência da taxa de câmbio sobre os preços, dada a grande participação dos preços administrados no IPCA, mas também da magnitude extremamente baixa do efeito riqueza na economia brasileira.

A peculiaridade das LFTs, no que se refere ao seu mecanismo de formação de preço, bem como sua majoritária participação na DMFi geram uma série de problemas para a obtenção de uma política monetária com maior eficácia. Além de eliminar parte do efeito riqueza da política monetária e, 
ainda, gerar um efeito renda positivo, a existência de tais títulos faz com que a riqueza financeira se concentre predominantemente no curto prazo.

A lógica do curto prazo tanto desestimula o crédito na economia, já que a Selic opera como um custo de oportunidade, quanto impede um maior crescimento do mercado de capitais no país. Esses fatos, sem dúvida, também operam como fatores limitadores da capacidade de crescimento da economia brasileira, pois as empresas passam a ter de pagar um custo de oportunidade muito alto no financiamento de seus projetos.

Dessa forma, a existência das LFTs, ao oferecer uma garantia aos investidores de uma aplicação de um dia feita repetidamente, não só dificulta uma queda mais expressiva e continuada dos juros no país como atua também negativamente sobre o crescimento econômico. Dadas essas duas conseqüências, a própria queda da dívida pública como proporção do PIB fica comprometida.

Além disso, a melhora na composição da dívida, como a observada a partir do final de 2005, parece ficar limitada à continuidade das expectativas positivas quanto à conjuntura econômica. Visto que as compras de títulos prefixados são feitas predominantemente por agentes financeiros, submetidos a modelos de gestão de risco do tipo Var e estimulados por perspectivas de ganhos de capital, o próprio processo de aumento da duração da dívida encontra um limite. Nesse contexto, qualquer mudança de cenário não só reverte as melhorias obtidas na duração e alongamento da dívida pública, como impõe à autoridade monetária a recompra ou troca dos títulos prefixados.

A manutenção das LFTs, criadas no Plano Cruzado e mantidas até hoje como os principais indexadores da dívida pública, precisa ser revista urgentemente. A manutenção de tais títulos não é condizente com a estabilidade de preços e a construção de uma economia com sólidos fundamentos. Como bem define Carneiro (2006), se os ganhos obtidos nos últimos anos com a estabilidade de preços não forem suficientes para baixar os juros, então os efeitos da vitória sobre a inflação serão parcialmente devolvidos.

Como pode ser confirmado pela simulação feita, a elevação da duração da dívida, que depende da eliminação das LFTs como principal indexador, é condição necessária para que se possa aumentar a eficácia da política monetária. Além disso, tal mudança possibilita que choques adversos sobre a in- 
flação possam ser combatidos com menores custos fiscais, viabilizando a retomada dos investimentos públicos.

Deve-se considerar que a própria lógica de ajuste fiscal deve ser revista. É necessário diminuir o maior custo fiscal existente, o pagamento de juros, para que investimentos e gastos públicos necessários possam ser retomados. Não sendo esse o caso, o que teremos é a continuidade do perverso mecanismo de transferência de renda, que era visto como um dos males da alta inflação. Para isso, é necessário urgentemente que a eficácia da política monetária seja elevada e, portanto, que o efeito riqueza passe a operar mais expressivamente.

A estabilidade de preços obtida precisa se desvincular dos mecanismos de política monetária impostos 20 anos atrás como necessários para uma saída do Plano Cruzado sem o desencadear de uma crise sistêmica. Caso isso não ocorra, tanto o crescimento econômico ficará comprometido, quanto o ajuste fiscal ficará limitado à retirada do estado como força responsável pela assistência social, regulação econômica e interventor na construção de condições favoráveis à retomada do crescimento econômico sustentável e socialmente justo.

\section{NOTAS}

1. O efeito riqueza pode ser entendido como o impacto de variações da taxa de juros sobre a riqueza financeira dos agentes e, por esse canal, sobre os níveis de consumo e investimento dos agentes econômicos.

2. Para uma discussão sobre a criação dos títulos com indexação à taxa de juros fixada pelo Banco Central, bem como do contexto em que isso ocorreu, ver Arida (2006) e Resende (2006).

3. Essa mudança institucional está definida pelos $₫ \S 1^{\circ}$ e $2^{\circ}$ do art. 164 da Constituição Federal.

4. Mesmo que o efeito riqueza não seja eliminado por completo, o que parece ser o caso, sua redução pode implicar que a valorização da riqueza derivada do aumento dos juros supere a perda de capital.

5. Essa metodologia de cálculo do preço das LFTs pode ser encontrada no manual do Tesouro Nacional sobre a metodologia de cálculo dos títulos públicos ofertados.

6. Dado que a taxa Selic representa um custo de oportunidade para os agentes, a taxa de deságio tende a estar muito próxima de zero, elevando-se em momentos de stress.

7. A data em que ocorre o vencimento não é contada. 
8. O Banco Central do Brasil define a duração das LFTs como 0,03, ou seja, é considerado que tal título tem a duração de um dia (1/30).

9. Esse é o caso das Letras do Tesouro Nacional, que são títulos prefixados e sem pagamento de cupom.

10. O preço do título em carteira é dado pela sua compra no mercado primário.

11. As regras de marcação a mercado podem ser consultadas na Circular no 3.086, de 15 de fevereiro de 2002, do Banco Central do Brasil.

12. Nesse caso, o $i$ do denominador representa a taxa de juros Selic.

13. O Banco Central e o Tesouro Nacional iniciaram, no segundo semestre de 2001, um processo de transição, visando à adaptação das instituições para o fim das emissões de títulos cambiais pela autoridade monetária, conforme determina a Lei de Responsabilidade Fiscal.

14. Atualmente têm ocorrido emissões de NTN-B e NTN-C. Enquanto a duração/prazo médio das notas série B e C são, respectivamente, 48 e 78 meses, as notas de série D apresentam prazo médio de 13 meses (BCB-DEMAB).

15. De fato, a definição usual para esses títulos é pós-fixados. Contudo, como o interesse neste trabalho é discutir o impacto da taxa de juros sobre o preço do ativo, e como esta é préfixada, pode-se considerar que as três Notas do Tesouro citadas são préfixadas.

16. Utilizou-se a posição em custódia para captar o saldo líquido de operações realizadas com compromisso de recompra e revenda.

17. É importante observar que até o início do segundo semestre de 1998 os prazos de duração e maturidade eram muito próximos. A partir da crise russa marca-se uma grande diferença entre a evolução da duração e do prazo médio.

18. Atualmente não são mais emitidas as NTNs de série H, E e S. Esses títulos apresentavam prazos médios bem menores do que as notas de série $\mathrm{C}$ e $\mathrm{B}$.

19. Apesar de a base das taxas de juros ser a taxa Selic, o mercado acabou elegendo a taxa do CDI como benchmark, pois ela é formada pelo próprio mercado. As taxas Selic e CDI são, em geral, muito próximas e até iguais quando o mercado não espera nenhum movimento da taxa básica pela autoridade monetária (Securato, 2005). Quando o mercado espera um aumento (queda) da taxa Selic, a taxa CDI tende a ficar maior (menor) que a própria Selic.

20. Para uma discussão mais detalhada desse processo, ver os autores citados.

21. A existência de valores negativos nesse tipo de modelo de impulso resposta não é uma incoerência, dado que o objetivo é o de somente acompanhar a trajetória das variáveis. Ver, por exemplo, os modelos descritos por Walsh e Stiglitz (2006).

22. Entenda-se como "ponto ótimo" aquele em que os custos sociais da inflação e os benefícios de uma baixa taxa de inflação estariam se compensando.

23. O termo $a_{2} D r_{\mathrm{t}}$ representa o fator de desconto da riqueza financeira (DMFi), ponderada por sua participação no produto, dada a taxa de juros. Assim como os títulos públicos individuais (p. 80 e 82), o valor presente do estoque da DMFi pode ser obtido a partir da 
taxa de juros, devidamente ponderada pela Duration. Deve-se ter presente que o modelo apresentado considera somente o impacto da taxa de juros sobre o produto através da riqueza financeira, desconsiderando seu impacto, por simplificação, através do consumo e investimento.

24. Sobre o Método dos Coeficientes Indeterminados, ver McCallum (1989), especialmente o capítulo 8.

25. Essa forma de cálculo do conceito matemático da Duration pode ser encontrada em Cavalcante; Zeppelini e Perini (2000).

26. Fonte: IPEADATA.

27. Deve-se salientar que pequenas diferenças da inflação em relação às expectativas devemse à própria aplicação do Método dos Coeficientes Indeterminados.

\section{REFERÊNCIAS BIBLIOGRÁFICAS}

ARIDA, P. As Letras Financeiras do Tesouro em seu vigésimo aniversário. In: BACHA, E. L.; OLIVEIRA, L. C. Mercado de capitais e dívida pública. Rio de Janeiro: Contra Capa, 2006.

BANCO CENTRAL DO BRASIL: banco de dados: Disponível em: <http://www.bacen.gov.br>.

BRASIL. Artigo 164 da Constituição Federal de 1988. Estabelece que a competência da União para emitir moeda será exercida exclusivamente pelo Banco Central. Constituição da República Federativa do Brasil. 17. ed. São Paulo, 5 out. 1988, p. 164.

Circular 3.086. Estabelece normas de marcação a mercado pelo Banco Central do Brasil. Banco Central do Brasil, 15 fev. 2002.

CARNEIRO, D. D. Letras Financeiras do Tesouro e normalidade financeira: haverá um "peso problem"? In: BACHA, E. L.; OLIVEIRA, L. C. Mercado de capitais e dívida pública. Rio de Janeiro: Contra Capa, 2006. p. 197-218.

; WU, T. A qualidade da dívida pública brasileira. Instituto de Estudos de Política Econômica, Casa das Garças. Texto para Discussão, n. 9, nov. 2005.

CAVALCANTE, F.; ZEPPELINI, P. D.; PERINI, C. R. Duration: avaliando o risco de mudanças na taxa de juros. Parte II, 2000. Disponível em: $<$ http://www.expresstraining.com.br $>$.

FERREIRA, C. K. L.; ROBOTTON, M. F.; DUPITA, A. B. Política monetária e alongamento da dívida pública: uma proposta de discussão. Texto para Discussão, PUC-SP, n. 9, 2004.

FRANCO, G. H. B. Notas sobre crowding out, juros altos e Letras Financeiras do Tesouro. In: BACHA, E. L.; OlIVEIRA, L. C. Mercado de capitais e dívida pública. Rio de Janeiro: Contra Capa, 2006. p. 273-298.

IPEA: BANCO DE DADOS. Disponível em: http://www.ipea.gov.br/SobreIPEA/Ipeadata.

LUDVIGSON, S.; STEINDEL, C.; LETTAU, M. Monetary policy transmission through the consumption-wealth channel. Economic Policy Review, maio, 2002. 
MARQUES, N. F. da S. A experiência brasileira no manejo da política monetária para a subsistência do mercado de dívida pública, com a despoupança do setor público. II Prêmio STN de monografias, 1997. Disponível em: <http:tesouro.fazenda.gov.br/Premio_TN/IIpremio>.

MCCALlUM, B. T. Monetary Economics: theory and policy. [s.l.]: Prentice Hall, 1989, 480 p.

MINELLA, A. et al. Inflation targeting in Brazil: lessons and challenges. Banco Central do Brasil. nov. 2002. Disponível em: <http://www.bcb.gov.br/pec/wps/port/default.asp\#2002 >. Acesso em: 14 fev. 2003.

MOURA, A. R. Letras Financeiras do Tesouro: quousque tandem. In: BACHA, E. L.; OLIVEIRA, L. C. Mercado de capitais e divida pública. Rio de Janeiro: Contra Capa, 2006. p. 245-254.

PASTORE, A. C. Por que a política monetária perde eficácia? Revista Brasileira de Economia, FGV, v. 50, abr. 1996.

RESENDE, ANDRÉ L. Em defesa dos títulos de indexação financeira. In: BACHA, E. L.; OLIVEIRA, L. C. Mercado de capitais e dívida pública. Rio de Janeiro: Contra Capa, 2006.

SECURATO, J. R. Cálculo financeiro das tesourarias, bancos e empresas. 3. ed. São Paulo: Saint Paul, 2005.

TESOURO NACIONAL. Metodologia de cálculo dos títulos públicos ofertados no Tesouro Direto. 4. ed. Disponível em: <http://www.tesouro.fazenda.gov.br/tespuro_direto/download/ metodologia.pdf.

WALSH, C.; STIGLITZ, J. E. Principles of macroeconomics. IE-WW Norton, 2006.552 p. 